\title{
Teaching Medical Students to Help Patients Quit Smoking: Outcomes of a 10-School Randomized Controlled Trial
}

Judith K. Ockene, PhD, MEd, MA' ', Rashelle B. Hayes, PhD' ', Linda C. Churchill, MS', Sybil L. Crawford, $P h D^{\prime}$, Denise G. Jolicoeur, MPH, $C H E S^{l}$, David M. Murray, PhD', Abigail B. Shoben, PhD ${ }^{3}$, Sean P. David, MD, DPhil', Kristi J. Ferguson, PhD ${ }^{5}$, Kathryn N. Huggett, PhD ${ }^{6}$, Michael Adams, $M D^{7}$, Catherine A. Okuliar, $M D^{7}$, Robin L. Gross, $M D^{7}$, Pat F. Bass III, MD, MS, MPH ${ }^{8}$, Ruth B. Greenberg, PhD', Frank T. Leone, MD ${ }^{10}$, Kola S. Okuyemi, MD ${ }^{17}$, David W. Rudy, MD ${ }^{12}$, Jonathan B. Waugh, $P h D^{13}$, and Alan C. Geller, MPH, RN ${ }^{14}$

\begin{abstract}
'Division of Preventive and Behavioral Medicine, Department of Medicine, University of Massachusetts Medical School, Worcester, MA, USA; ${ }^{2}$ Biostatistics and Bioinformatics Branch; Division of Intramural Population Health Research, Eunice Kennedy Shriver National Institute of Child Health and Human Development, National Institutes of Health, Bethesda, MD, USA; ${ }^{3}$ Division of Biostatistics, College of Public Health, The Ohio State University, Columbus, $\mathrm{OH}, \mathrm{USA} ;{ }^{4}$ Center for Education \& Research in Family and Community Medicine, Division of General Medical Disciplines, Department of Medicine, Stanford University School of Medicine, Palo Alto, CA, USA; 5 University of lowa Carver College of Medicine, lowa City, IA, USA; 'Department of Medicine, Creighton University School of Medicine, Omaha, NE, USA; ${ }^{6}$ Department of Medicine, Georgetown University Hospital, Washington, DC, USA; ${ }^{8}$ Louisiana State University Health Shreveport, Shreveport, LA, USA; ${ }^{\circ}$ University of Louisville School of Medicine, Louisville, KY, USA; ${ }^{10}$ Division of Pulmonary, Allergy and Critical Care Medicine, Perelman School of Medicine, University of Pennsylvania, Philadelphia, PA, USA; " Department of Family and Community Health, University of Minnesota School of Medicine, Minneapolis, MN, USA; ${ }^{12}$ University of Kentucky College of Medicine, Lexington, KY, USA; ${ }^{13}$ Clinical and Diagnostics Sciences Department, School of Health Professions, UAB Lung Health Center, University of Alabama at Birmingham, Birmingham, AL, USA; ${ }^{14}$ Department of Social and Behavioral Sciences, Harvard School of Public Health, Boston, MA, USA.
\end{abstract}

BACKGROUND: Early in medical education, physicians must develop competencies needed for tobacco dependence treatment.

OBJECTIVE: To assess the effect of a multi-modal tobacco dependence treatment curriculum on medical students' counseling skills.

DESIGN: A group-randomized controlled trial (20102014) included ten U.S. medical schools that were randomized to receive either multi-modal tobacco treatment education (MME) or traditional tobacco treatment education (TE).

SETTING/PARTICIPANTS: Students from the classes of 2012 and 2014 at ten medical schools participated. Students from the class of $2012(N=1345)$ completed objective structured clinical examinations (OSCEs), and $50 \%$ $(N=660)$ were randomly selected for pre-intervention evaluation. A total of $72.9 \%$ of eligible students $(N=1096)$ from the class of 2014 completed an OSCE and $69.7 \%$ $(N=1047)$ completed pre and post surveys.

INTERVENTIONS: The MME included a Web-based course, a role-play classroom demonstration, and a clerkship booster session. Clerkship preceptors in MME schools participated in an academic detailing module and were encouraged to be role models for third-year students.

MEASUREMENTS: The primary outcome was student tobacco treatment skills using the 5As measured by an objective structured clinical examination (OSCE) scored on a 33-item behavior checklist. Secondary outcomes

Received April 30, 2015

Revised July 9, 2015

Accepted August 25, 2015

Published online September 21, 2015 were student self-reported skills for performing $5 \mathrm{As}$ and pharmacotherapy counseling.

RESULTS: Although the difference was not statistically significant, MME students completed more tobacco counseling behaviors on the OSCE checklist (mean 8.7 [SE 0.6] vs. mean 8.0 [SE 0.6], $p=0.52$ ) than TE students. Several of the individual Assist and Arrange items were significantly more likely to have been completed by MME students, including suggesting behavioral strategies ( $11.8 \%$ vs. $4.5 \%, p<0.001)$ and providing information regarding quitline $(21.0 \%$ vs. $3.8 \%, p<0.001)$. MME students reported higher self-efficacy for Assist, Arrange, and Pharmacotherapy counseling items ( $p s \leq 0.05$ ).

LIMITATIONS: Inclusion of only ten schools limits generalizability.

CONCLUSIONS: Subsequent interventions should incorporate lessons learned from this first randomized controlled trial of a multi-modal longitudinal tobacco treatment curriculum in multiple U.S. medical schools. NIH Trial Registry Number: NCT01905618

KEY WORDS: tobacco dependence treatment; counseling; medical school curriculum; medical student behaviors; randomized controlled trial; objective structured clinical examination.

J Gen Intern Med 31(2):172-81

DOI: $10.1007 / \mathrm{s} 11606-015-3508-y$

(c) Society of General Internal Medicine 2015

\section{INTRODUCTION}

Physicians have contact with at least $70 \%$ of adult smokers in the United States annually ${ }^{1}$ and have an essential role in helping patients stop smoking. As brief interventions can have 
a substantial impact on adult smokers, ${ }^{2,3}$ the U.S. Preventive Services Task Force gives physician-delivered tobacco treatment interventions (e.g. 5A counseling, "Ask, Advise, Assess, Assist, Arrange") an "A" recommendation, indicating that physicians should offer this service at every office visit. Unfortunately, use of the $5 \mathrm{As}$ among physicians is limited ${ }^{1,4-6}$ as is the amount of tobacco treatment training that physicians receive. ${ }^{7-11}$ Developing the competencies needed for tobacco dependence treatment and integrating them into routine practice should start early in medical education. ${ }^{12}$

Medical students are inadequately prepared to help patients modify health behaviors such as tobacco use. ${ }^{13}$ A curriculum that optimally combines didactics, interactive counseling practice through role-play or the use of standardized patients, and observed clinical experiences with smokers is not the norm. ${ }^{14}$ Earlier reports indicated that U.S. medical school curricula devote only $4 \mathrm{~h}$ during the 4 years to training for tobacco dependence treatment. ${ }^{15}$ Therefore, there is a gap between the acknowledged importance of developing tobacco dependence treatment skills and the level of tobacco dependence treatment training provided in medical school. ${ }^{13}$ This is unfortunate, given that competency in tobacco dependence treatment is now recommended as a core graduation requirement for all new physicians and other healthcare professionals. ${ }^{16,17}$

The goal of the current study (MSQuit) was to develop, implement, and evaluate a comprehensive multi-modal education (MME) intervention for teaching the effective delivery of tobacco dependence treatment to medical students. We hypothesized that MME delivered over multiple school years would improve medical students' tobacco dependence treatment skills beyond traditional education (TE). MSQuit compared the two educational interventions in the context of a group-randomized controlled trial.

\section{METHODS}

\section{Trial Design}

Ten U.S. medical schools were pair-matched (see "PairMatching and Randomization" section) and randomized to MME or TE curriculum. The primary outcome was student performance on a tobacco-specific objective structured clinical examination (OSCE) case given to third-year medical students. Using a cross-sectional design, OSCE scores for students from the class of 2014 who participated in MME or TE were compared with those of students at the same schools from an earlier cohort (class of 2012) who did not participate in the intervention. Using a cohort design, the secondary outcomes of self-reported skills (i.e. self-efficacy) for performing each $5 \mathrm{~A}$ behavior and pharmacotherapy counseling among MME and TE third-year students (class of 2014) were compared. ${ }^{18}$

\section{Participating Schools}

The ten medical schools that participated in the study are noted in our previous publication. ${ }^{18}$ Schools met the following criteria: 1) an enrollment of $\geq 90$ matriculating first-year (MS1) students; 2 ) $\leq 4 \mathrm{~h}$ of tobacco treatment training over 4 years of medical school; 3) a family medicine or internal medicine clerkship for third-year (MS3) students; and 4) a standard evaluation of MS3s using an OSCE examination, with agreement by the medical school to include a new tobacco case. Institutional review boards at each participating medical school approved the study. Three of the ten schools had participated in an earlier study of tobacco dependence treatment training in medical schools; ${ }^{11}$ the other seven were recruited through networks with colleagues. Schools were both private $(N=3)$ and public $(N=7)$, geographically diverse, and located in both inner-city and outlying areas.

\section{Pair Matching and Randomization}

Before randomization, schools were pair-matched based on their total overall school ranking in self-reported skills for performing the 5As and pharmacotherapy counseling (see Primary and Secondary Outcomes Measures) via a survey of third-year medical students (MS3) from the class of 2011. Schools were then ranked based on the school's average score, and were randomized to MME or TE with their matched school.

\section{EDUCATIONAL INTERVENTIONS}

\section{MME: Multi-Modal Education}

All research personnel and site principal investigators from each of the ten schools participated in the iterative development of each MME learning component. The MME intervention consisted of components that took place either in the first or third year of medical school. These included 1) a 4-h selfpaced Web-based course for MS1s covering all 5As, with particular emphasis on Assist and Arrange and pharmacotherapy counseling; 2) a role-play classroom demonstration and practice implemented in tandem with the Web course; and 3) a clerkship booster session during the third-year family or internal medicine clerkship rotation that reinforced prior tobacco dependence treatment instruction.

Clerkship preceptors from either the family or internal medicine clerkship attended a 30- to 60-min individual or group academic detailing ${ }^{19}$ session reviewing tobacco dependence treatment guidelines, as well as how to model, observe, instruct, and provide critical feedback to students in the specific 5A and pharmacotherapy counseling skill set for tobacco treatment. MME students, therefore, participated in an enhanced clerkship rotation in which students and preceptors were strongly recommended to work together with patients who smoked. MME schools were encouraged to continue providing their traditional tobacco treatment education concurrent with MME implementation. 


\section{TE: Traditional Education}

Students and preceptors in the five TE schools continued their traditional tobacco education. This curriculum over the 4 years of medical school was reported to be $\leq 4 \mathrm{~h}$ in duration and varying in content. Traditional teaching was largely didactic, interspersed among basic science and behavioral counseling classes in medical school years 1 and 2. Some schools also included tobacco case studies as part of their behavioral counseling role-plays taught to first- or second-year students.

\section{Intervention Fidelity}

Each MME component was provided to MME schools and their faculty instructors with standardized written guidelines, instructions, objectives, and discussion points to ensure that students would receive the intervention in a similar manner and within a specified time frame (e.g. during MS1 year). Academic detailers (ADs) were first trained by UMMS researchers in an 8-h training session, and received follow-up supervision. Prior to the teaching of preceptors, ADs practiced their sessions with "practice participants", and all sessions were audiotaped. Each AD completed fidelity checklists after each session with preceptors to ensure that all pertinent topics were covered.

\section{Primary and Secondary Outcomes Measures}

The primary outcome, observed 5As plus pharmacotherapy counseling for tobacco dependence treatment, was measured by a structured OSCE, a standard method for evaluating medical student skills at U.S. medical schools. ${ }^{20,21}$ OSCEs were implemented within the context of existing clinical skills assessments. School-level scores from the class of 2012 were compared with school-level scores from the class of 2014. About $50 \%$ of the OSCEs for the class of 2012 were randomly selected for coding in order to provide a pre-intervention school-level comparison. In contrast, $100 \%$ of OSCEs for the class of 2014 were coded. This nested cross-sectional design $^{22}$ was chosen because OSCEs are not given to MS1s.

OSCEs were videotaped and then scored using a 33behavior checklist (Yes/No items) covering multiple aspects of each $5 \mathrm{~A}$ behavior and four additional items for communication skills that were scored from $1=$ poor to $5=$ excellent; total scores ranged from 4 to 20 . The development and quality assurance measure related to the study checklist are described in Mazor and colleagues (in press). Previous research by Mazor $^{23}$ demonstrated the effectiveness of such an approach, and the 2008 update to the clinical guidelines ${ }^{24}$ includes a recommendation to utilize interviewing strategies for increasing motivation. Items were approved by a scientific advisory group of external tobacco researchers and clinicians, and are based on clinical guidelines. ${ }^{24}$ Three blinded and trained raters viewed the video recording of the OSCE and completed the checklist. A random selection of $10 \%$ of raters' scoring was compared against the rating by a "gold-standard" supervisor, with little variation noted. The gold-standard supervisor received extensive training and practice in completing the checklist from the study staff responsible for developing the checklist. Standardized patients portraying the tobacco case were not responsible for scoring student performance on this OSCE. Secondary outcomes were student self-reported skill level for performing each of the 5As and pharmacotherapy counseling (6 items total). All students from the class of 2014 completed a questionnaire as MS1s and again at postintervention as MS3s. Items included, "Asking about smoking at every visit", "Advising smokers to quit", "Assessing smokers' willingness to quit", "Assisting smokers to develop a quit plan", "Arranging follow-up contact regarding smoking", and "Discussing and prescribing pharmacotherapy options". Although the discussion of pharmacotherapy can be considered an "Assist" behavior, this was asked as a separate item to assess self-efficacy for this specific skill. Each item was dichotomized as "moderately or very skilled" vs. "not at all or somewhat skilled".

\section{Intervention Tracking and Dosage Measures}

Study coordinators at each school tracked each student's participation in the role-play and booster MME component (Yes/ No). The study-tracked total MME intervention dose received per student was computed as the total number of components completed (0 through 3). Each school's academic detailer also recorded the attendance of preceptors in their academic detailing sessions. Third-year students at MME and TE schools were also asked whether they had participated in a Webbased course and role-play classroom demonstration regarding tobacco dependence treatment. In addition, students completed a series of questions to assess the extent of the clerkship preceptors' provision of tobacco training instruction for students. Students rated on a four-point scale $(1=$ Strongly disagree to $4=$ Strongly agree) how much they agreed with seven statements related to their preceptor providing them with clear instruction, feedback, and training regarding tobacco dependence counseling. The self-reported total intervention dose was computed as the sum of having received each of the MME components (range 0 to 3 ).

\section{Other Relevant Measures}

Third-year students from both cross-sectional (MS3 students from the classes of 2012 and 2014) and cohort (MS1 and MS3 students from the class of 2014) designs also answered questions related to demographics (e.g. age, gender), their intended career choice (primary care, specialty, other, or unsure), and their smoking history (e.g. had they smoked $\geq 100$ cigarettes in their lifetime).

\section{Statistical Analysis}

The analyses of OSCE scores used a two-stage mixed model analysis of variance (ANCOVA) ${ }^{23,25}$ In the first stage, 20 (10 schools $\times 2$ time-points $)$ means were estimated from an ANCOVA for student-level OSCEs as a 
function of school, time-point, and their interaction. In the second stage, the ten post-intervention school means were regressed on intervention assignment and the corresponding pre-intervention school mean. This approach adjusted for the MME and TE comparison for baseline school means while accounting for within-school correlation.

Due to missing data on the OSCE scores for about $27 \%$ of the class of 2014 , we completed a sensitivity analysis using a multiple imputation approach appropriate for group-randomized controlled trials. ${ }^{26}$ The following items were used for imputation: baseline school mean, randomization assignment, history of smoking in the past 30 days, history of providing tobacco dependence treatment counseling or clinical work prior to medical school, frequency of tobacco dependence treatment instruction and observation during medical school, tobacco-related knowledge, and 5A self-efficacy and intentions. We used available data from the students' baseline and follow-up surveys to impute missing OSCE scores. Ten imputed datasets were combined to estimate the difference in mean OSCE scores for the MME and TE schools, adjusting for baseline mean OSCE score and treating school as a random effect, thereby mimicking the primary analysis.

The 5A and pharmacotherapy counseling self-efficacy skills outcome used a mixed-effects logistic regression, ${ }^{26}$ adjusting for student's own pre-intervention 5A and pharmacotherapy counseling dichotomized scores, treating school as a random effect.

To examine the association of MME "dosage" with total OSCE score, we used linear mixed modeling adjusting for the school-specific baseline mean total OSCE score, treating school as a random effect. We conducted two separate analyses for study-tracked dosage scores and student- reported dosage score. All analyses used SAS Version $9.3^{27}$ or $\mathrm{R}$ 2.15.2 statistical software. $^{28}$ Supplemental analyses of individual OSCE items did not adjust for multiple comparisons, focusing instead on consistency of condition-related differences across items.

\section{RESULTS}

\section{Participating Students}

There were $766 \mathrm{MS} 3 \mathrm{~s}$ (class of 2014) at MME schools who were eligible for the study. Of these, 565 (73.8\%) completed a third-year post-intervention OSCE, and 552 (72.1\%) completed both the baseline and post-intervention surveys. There were $737 \mathrm{MS} 3 \mathrm{~s}$ (class of 2014) at TE schools who were eligible for the study. Of these, $531(72.0 \%)$ completed a third-year post-intervention OSCE, and 495 (67.2\%) completed both the baseline and post-intervention surveys. Among students who completed OSCEs or follow-up self-efficacy surveys 2 years later, no MME vs. TE differences in baseline demographics or smoking history were noted (Table 1). Reasons for missing outcomes are reported in Fig. 1. On the follow-up survey, students reported their intended career as follows: primary care $(37 \%)$, medical specialty $(37 \%)$, other $(20 \%)$, and undecided (6\%); there were no other differences by study condition.

\section{MME Intervention Participation and Fidelity}

Among 612 eligible MME school students in the OSCE or self-efficacy analyses, study data objectively reported that $89.5 \%$ completed the Web-based course, $82.7 \%$ completed the role-play activity, and $83.5 \%$ completed the third-year booster session; $72.4 \%$ completed all three intervention components. Of the 268 eligible clerkship preceptors from the five MME schools, $83 \%$ participated in an academic detailing session. Self-reported receipt of each type of learning component was higher among MME than TE students at postintervention: $91.7 \%$ vs. $43.9 \%$ for receipt of any Webbased education $(p<0.001), 90.0 \%$ vs. $63.4 \%$ for receipt of any role-play participation $(p=0.008)$, and $51.5 \%$ vs. $38.3 \%$ for student-reported optimal preceptor training $(p=0.10)$.

Additionally, at post-intervention, a greater percentage of MME versus TE students reported $>5 \mathrm{~h}$ of tobacco education during their pre-clinical years $(42.4 \%$ vs. $21.8 \%, p=0.06)$. In general, among third-year students completing an internal medicine clerkship, MME students were more likely than TE students to agree that their preceptors provided clear

Table 1 Characteristics of Student Cohort by Randomization Assignment

\begin{tabular}{|c|c|c|c|c|c|c|}
\hline \multirow[b]{2}{*}{ Baseline Characteristics } & \multicolumn{3}{|c|}{ Students in OSCE Analyses } & \multicolumn{3}{|c|}{ Students in Third-Year Self-Efficacy (5A) Analyses } \\
\hline & $\begin{array}{l}\text { TE students, } \\
N=531^{*}\end{array}$ & $\begin{array}{l}\text { MME students, } \\
N=565^{*}\end{array}$ & $\begin{array}{l}\text { Total, } \\
N=1096\end{array}$ & $\begin{array}{l}\text { TE students, } \\
N=495\end{array}$ & $\begin{array}{l}\text { MME students, } \\
N=552\end{array}$ & $\begin{array}{l}\text { Total, } \\
N=1047\end{array}$ \\
\hline \multicolumn{7}{|l|}{ Gender, N (\%) } \\
\hline Male & $284(53.5)$ & $326(57.7)$ & $610(55.7)$ & $264(53.3)$ & $307(55.6)$ & $571(54.5)$ \\
\hline Female & $247(46.5)$ & $239(42.3)$ & $486(44.3)$ & $231(46.7)$ & $245(44.4)$ & $476(45.5)$ \\
\hline Age, mean (SD) & $23.2(2.0)$ & $23.4(2.5)$ & $23.4(2.3)$ & $23.2(2.0)$ & $23.5(2.5)$ & $23.4(2.3)$ \\
\hline \multicolumn{7}{|l|}{$\begin{array}{l}\text { Ever smoked } 100 \\
\text { cigarettes, } N(\%)\end{array}$} \\
\hline No & $431(89.6)$ & $468(90.4)$ & $899(90.0)$ & $435(89.1)$ & $494(89.8)$ & $929(89.5)$ \\
\hline Yes & $50(10.4)$ & $50(9.7)$ & $100(10.0)$ & $53(10.9)$ & $56(10.2)$ & $109(10.5)$ \\
\hline
\end{tabular}


a

\section{Consort Diagram / Flow Diagram \\ Primary Outcome OSCE data}

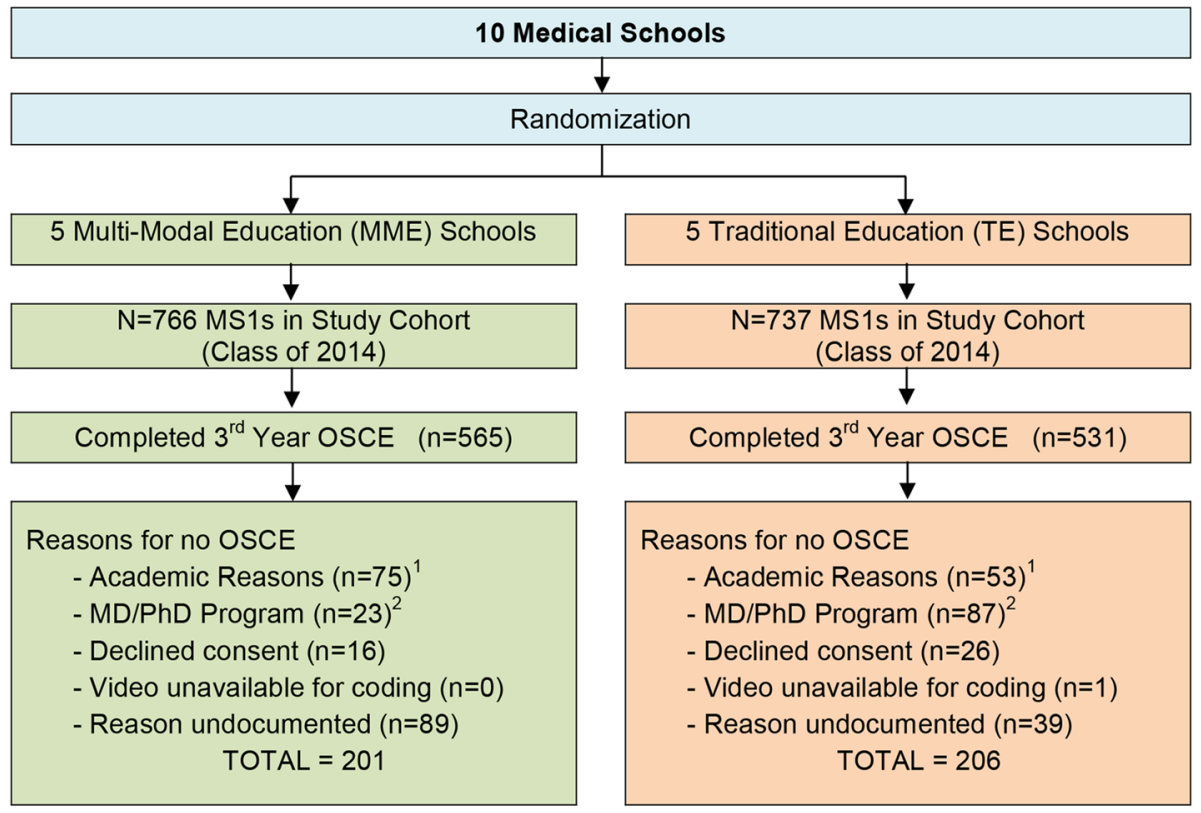

${ }^{1}$ Academic Reasons: Extended schedule or no longer enrolled ${ }^{2} \mathrm{MD} / \mathrm{PhD}$ Program: Not available to complete survey

b

\section{Study Cohort Consort Diagram / Flow Diagram 5A Self-Efficacy Survey Data}

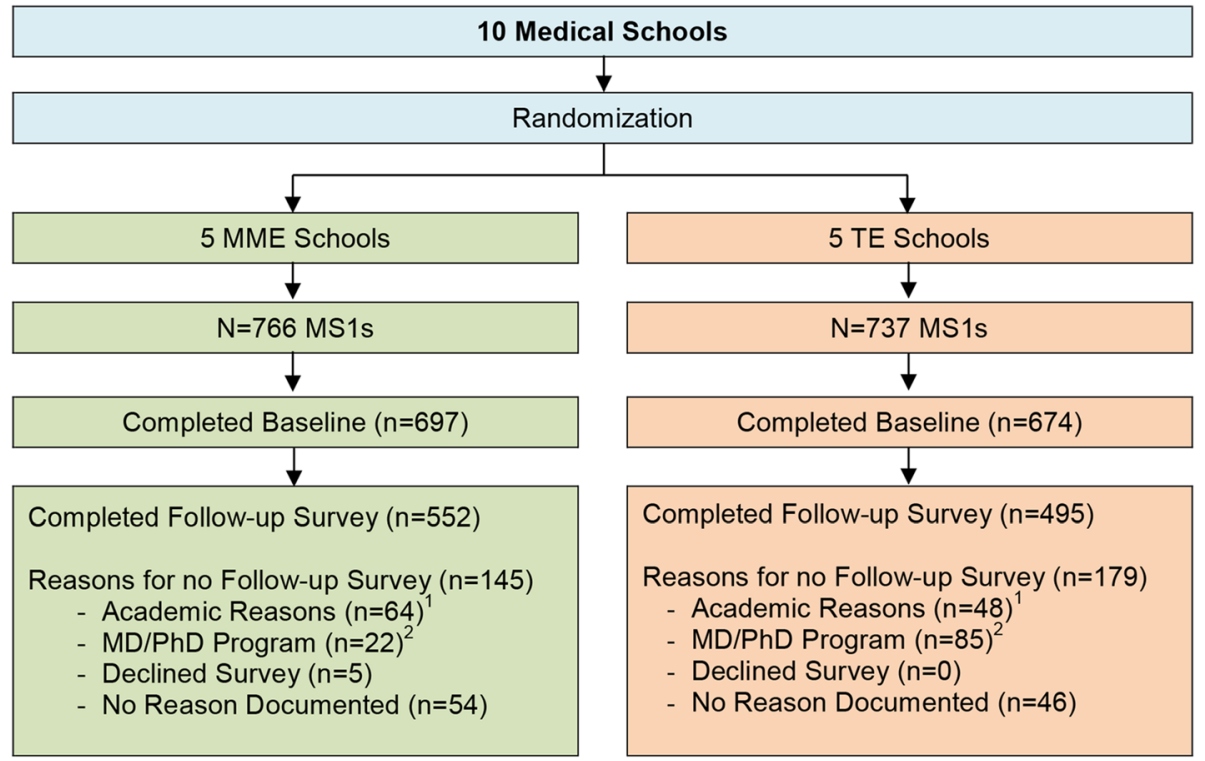

${ }^{1}$ Academic Reasons: Extended schedule or no longer enrolled

${ }^{2} \mathrm{MD} / \mathrm{PhD}$ Program: Not available to complete survey

Fig. 1 Consort diagram/flow diagram. a Primary outcome OSCE data. b 5A self-efficacy survey data

instruction, feedback, modeling and clear objectives, and responded to questions about tobacco counseling (Table 2).
Likewise, MME students from internal medicine clerkships reported a greater likelihood of advice for patients to quit 
Table 2 Student Ratings of Preceptor Teaching in Family Medicine and Internal Medicine by Randomized Assignment

\begin{tabular}{|c|c|c|c|c|c|c|}
\hline \multirow[b]{2}{*}{ Preceptor Variable: } & \multicolumn{3}{|c|}{ Family Medicine Clerkship } & \multicolumn{3}{|c|}{ Internal Medicine Clerkship } \\
\hline & Total $N$ & $\begin{array}{l}\text { \% Students in } \\
\text { clerkship who } \\
\text { agree / strongly agree }\end{array}$ & p value* & Total $N$ & $\begin{array}{l}\text { \% Students in } \\
\text { clerkship who } \\
\text { agree/strongly agree }\end{array}$ & $p$ value ${ }^{*}$ \\
\hline $\begin{array}{l}\text { A: Provided me with clear } \\
\text { instruction on ways to provide } \\
\text { tobacco counseling for my patients }\end{array}$ & & & 0.37 & & & 0.04 \\
\hline TE students & 522 & 64.9 & & 447 & 44.2 & \\
\hline MME students & 510 & 76.1 & & 538 & 69.7 & \\
\hline $\begin{array}{l}\text { B: Has given me feedback on my } \\
\text { tobacco dependence for my patients }\end{array}$ & & & 0.16 & & & 0.04 \\
\hline $\begin{array}{l}\text { TE students } \\
\text { MME students }\end{array}$ & $\begin{array}{l}523 \\
511\end{array}$ & $\begin{array}{l}33.7 \\
54.4\end{array}$ & & $\begin{array}{l}448 \\
540\end{array}$ & $\begin{array}{l}22.3 \\
47.2\end{array}$ & \\
\hline $\begin{array}{l}\text { C: Modeled ways that tobacco dependence } \\
\text { counseling should be provided }\end{array}$ & & & 0.86 & & & 0.08 \\
\hline $\begin{array}{l}\text { TE students } \\
\text { MME students }\end{array}$ & $\begin{array}{l}522 \\
511\end{array}$ & $\begin{array}{l}75.9 \\
74.4\end{array}$ & & $\begin{array}{l}447 \\
540\end{array}$ & $\begin{array}{l}51.8 \\
68.7\end{array}$ & \\
\hline $\begin{array}{l}\text { D: Gave clear objectives for tobacco } \\
\text { dependence counseling }\end{array}$ & & & 0.22 & & & 0.04 \\
\hline $\begin{array}{l}\text { TE students } \\
\text { MME students }\end{array}$ & $\begin{array}{l}523 \\
511\end{array}$ & $\begin{array}{l}31.6 \\
48.1\end{array}$ & & $\begin{array}{l}448 \\
539\end{array}$ & $\begin{array}{l}21.1 \\
46.6\end{array}$ & \\
\hline $\begin{array}{l}\text { E: Placed in records to remind staff to } \\
\text { advise patients to quit smoking }\end{array}$ & & & 0.17 & & & 0.05 \\
\hline $\begin{array}{l}\text { TE students } \\
\text { MME students }\end{array}$ & $\begin{array}{l}517 \\
506\end{array}$ & $\begin{array}{l}42.6 \\
51.3\end{array}$ & & $\begin{array}{l}445 \\
536\end{array}$ & $\begin{array}{l}30.3 \\
47.6\end{array}$ & \\
\hline $\begin{array}{l}\text { F: Educational materials prominently displayed } \\
\text { TE students } \\
\text { MME students }\end{array}$ & $\begin{array}{l}522 \\
507\end{array}$ & $\begin{array}{l}65.1 \\
67.0\end{array}$ & 0.78 & $\begin{array}{l}441 \\
537\end{array}$ & $\begin{array}{l}36.2 \\
57.4\end{array}$ & 0.05 \\
\hline $\begin{array}{l}\text { G: Responded to my questions regarding } \\
\text { tobacco counseling }\end{array}$ & & & 0.23 & & & 0.05 \\
\hline $\begin{array}{l}\text { TE students } \\
\text { MME students }\end{array}$ & $\begin{array}{l}504 \\
488\end{array}$ & 41.1 & & 438 & 25.0 & \\
\hline
\end{tabular}

smoking on medical records and educational materials being prominently displayed. For the family medicine clerkship, there were no differences between MME and TE students.

\section{OSCE Outcomes}

There was no significant difference between MME and TE students (Table 3 ) in total OSCE scores. This was consistent in the multiple imputation analyses (estimated mean MME 0.81 points higher, $p=0.41)$. MME students outperformed TE students on 27/33 items, and significant differences $(p s<0.05)$ were seen among 6 of the 33-item OSCE checklist (Table 3). MME students had higher communication scores than TE students, but this difference was not statistically significant $(p=0.21)$ (Table 3).

Specific findings included the fact that more than $70 \%$ of students in both MME and TE asked the standardized patient (SP) about their frequency of smoking per day and informed the SP that their cough was related to smoking. MME students, however, were more likely than TE students to report discussing the SP's confidence to quit, yet fewer than $20 \%$ of students provided this assessment. On each of the 18 Assist behavioral items, MME students scored higher (6 were related to nicotine replacement therapy [NRT] and other pharmacotherapy), and they were statistically significantly more likely than TE students to complete three of these items (Table 2). With regard to the Arrange items, MME students were significantly more likely than TE students to arrange for follow-up care via the quitline and to encourage discussion with a primary care provider.

\section{Association Between MME Dosage and Total OSCE Scores}

Total study-tracked intervention dose, relevant only for MME students, was positively associated with total OSCE score, as reflected in an estimated increase of 0.44 points (SE 0.24, $p=0.06$ ) with receipt of each additional intervention component. Among both MME and TE students, the magnitude of the association of total self-reported intervention dose, available for all students with total OSCE score, was weaker than for study-tracked intervention dose, reflected in a 0.12-point $(\mathrm{SE}=0.12, p=0.34)$ increase in total OSCE score with receipt of each additional intervention component.

\section{As and Pharmacotherapy Counseling Self- Efficacy Outcomes}

At post-intervention, a higher percentage of MME versus TE students agreed or strongly agreed that they were able to advise or assess $(p<0.10)$ and assist, 
Table 3 OSCE Scores and Individual OSCE Items: Comparison of MME and TE Educational Interventions

\begin{tabular}{|c|c|c|c|c|}
\hline & Mean (SE) & & & \\
\hline Scores: & $\mathrm{TE}(N=531)$ & & $\operatorname{MME}(N=571)$ & $\mathrm{p}$ value \\
\hline Total number of items performed (range $0-33$ ) & $8.03(0.62)$ & & $8.71(0.62)$ & 0.52 \\
\hline Communication skill (sum of 4 items, range 4-20) & $11.64(0.22)$ & & $12.08(0.22)$ & 0.21 \\
\hline & $\begin{array}{l}\text { \% Students } \\
\text { performing } \\
\text { each item }\end{array}$ & & & \\
\hline & $\operatorname{TE}(N=531)$ & $\operatorname{MME}(N=571)$ & $\begin{array}{l}\text { Odds ratio }(95 \% \mathrm{CI}) \text {, } \\
\text { MME vs. TE (ref) }\end{array}$ & $p$ value \\
\hline ASK: & & & & \\
\hline Asked how much patient smokes per day & 89.6 & 86.3 & $0.73(0.30,1.78)$ & 0.42 \\
\hline Asked how soon after waking patient smokes ${ }^{(a)}$ & 0.2 & 0.3 & $1.56(0.05,45.30)$ & 0.78 \\
\hline Asked how long patient has been smoking & 77.2 & 71.2 & $0.73(0.25,2.13)$ & 0.51 \\
\hline ADVISE: & & & & \\
\hline Advised patient to quit smoking in clear manner & 51.3 & 60.9 & $1.48(0.62,3.51)$ & 0.31 \\
\hline Informed patient that cough related to smoking ${ }^{(b)}$ & 70.9 & 74.3 & $1.19(0.87,1.62)$ & 0.27 \\
\hline ASSESS: & & & & \\
\hline Invited additional discussion of tobacco use & 13.5 & 11.7 & $0.84(0.27,2.68)$ & 0.74 \\
\hline Prompted discussion regarding readiness to quit & 66.0 & 73.9 & $1.46(0.63,3.37)$ & 0.32 \\
\hline Asked about reasons to consider quitting & 8.9 & 18.3 & $2.31(0.86,6.22)$ & 0.09 \\
\hline Prompted discussion regarding confidence in ability to quit & 2.1 & 9.8 & $5.19(1.54,17.57)$ & 0.01 \\
\hline Congratulated patient for cutting down & 51.6 & 49.3 & $0.91(0.47,1.77)$ & 0.75 \\
\hline Prompted discussion regarding barriers & 13.2 & 12.3 & $0.92(0.29,2.96)$ & 0.88 \\
\hline ASSIST: & & & & \\
\hline Asked about past quit attempts & 51.8 & 55.6 & $1.16(0.53,2.57)$ & 0.65 \\
\hline Asked about success/difficulties during past quit attempts & 25.5 & 32.1 & $1.38(0.64,2.98)$ & 0.37 \\
\hline Discussed strategies in past quit attempts & 19.9 & 25.1 & $1.35(0.31,5.94)$ & 0.64 \\
\hline Asked why started smoking again (a) & 0.8 & 3.2 & $4.01(0.43,37.44)$ & 0.19 \\
\hline Asked about triggers & 2.0 & 6.7 & $3.51(0.59,21.01)$ & 0.14 \\
\hline Elicited views of behavioral strategies & 0.5 & 2.1 & $3.94(0.37,42.05)$ & 0.22 \\
\hline Suggested behavioral strategies ${ }^{(b)}$ & 4.5 & 11.8 & $2.82(1.64,4.84)$ & $<0.001$ \\
\hline Asked for reaction to behavioral strategies & 0.4 & 1.6 & $4.59(0.67,31.34)$ & 0.11 \\
\hline Elicited views of medications & 18.7 & 27.5 & $1.65(1.01,2.69)$ & 0.05 \\
\hline Presented info regarding nicotine replacement therapy & 48.0 & 63.3 & $1.87(1.12,3.11)$ & 0.02 \\
\hline Presented info regarding varenicline & 24.3 & 32.5 & $1.50(0.67,3.37)$ & 0.27 \\
\hline Presented info regarding bupropion & 21.8 & 28.5 & $1.43(0.84,2.42)$ & 0.16 \\
\hline Asked for reaction to medication options & 18.6 & 29.6 & $1.83(0.98,3.45)$ & 0.06 \\
\hline Info regarding counseling plus medications & 1.2 & 1.8 & $1.44(0.25,8.38)$ & 0.62 \\
\hline Asked who could be helpful & 7.4 & 11.1 & $1.57(0.52,4.74)$ & 0.36 \\
\hline Discussed setting quit date & 11.6 & 13.0 & $1.14(0.49,2.66)$ & 0.73 \\
\hline Summarized treatment plan options & 10.2 & 11.9 & $1.19(0.51,2.76)$ & 0.63 \\
\hline Elicited response to plan & 7.0 & 9.2 & $1.35(0.42,4.38)$ & 0.55 \\
\hline ARRANGE: & & & & \\
\hline Provided information regarding quitline & 3.8 & 21.0 & $6.69(3.76,11.88)$ & $<0.001$ \\
\hline Discussed other referral options & 4.7 & 2.7 & $0.56(0.23,1.37)$ & 0.20 \\
\hline Recommended follow-up visit & 15.7 & 20.0 & $1.34(0.55,3.24)$ & 0.47 \\
\hline Encouraged discussion with primary care provider ${ }^{\dagger}$ & 0.9 & 5.6 & $6.49(1.92,21.91)$ & 0.004 \\
\hline
\end{tabular}

*Not adjusted for random school effect, as estimated random effect variance was 0 \%Not adjusted for school-specific comparison percentage due to multiple schools with a value of $0 \%$

Values in bold indicate statistical significance

arrange, and provide pharmacotherapy counseling $(p<0.05)$ (Fig. 2).

\section{DISCUSSION}

In this randomized study of ten U.S. medical schools, MME students receiving a combination of a Web-based course, role-play classroom demonstration, and preceptor-facilitated tobacco dependence treatment training and a booster session as MS1s and MS3s, respectively, were more likely to perform several tobacco dependence treatment-related 5A and pharmacotherapy counseling behaviors on an OSCE checklist, but demonstrated no overall change in total OSCE score relative to TE students. However, MME students were more likely to report higher self-efficacy skills for many $5 \mathrm{~A}$ and pharmacotherapy counseling tobacco dependence behaviors.

At study inception, we anticipated that performance on the OSCE and self-report on the performance of the $5 \mathrm{As}$ and pharmacotherapy counseling would evaluate different aspects of student mastery of tobacco dependence treatment competencies. OSCEs attempt to measure actual observed practice, although they provide only a snapshot of student skills in a simulated clinical situation. Student self-report seeks to measure the student's self-efficacy in tobacco dependence treatment skills that may or may not be associated with actual performance, and possibly subject to over- or underestimation.

The MSQuit study provided a competency-based multimodal curriculum with individual components that were evaluated in earlier studies with medical students and for teaching 


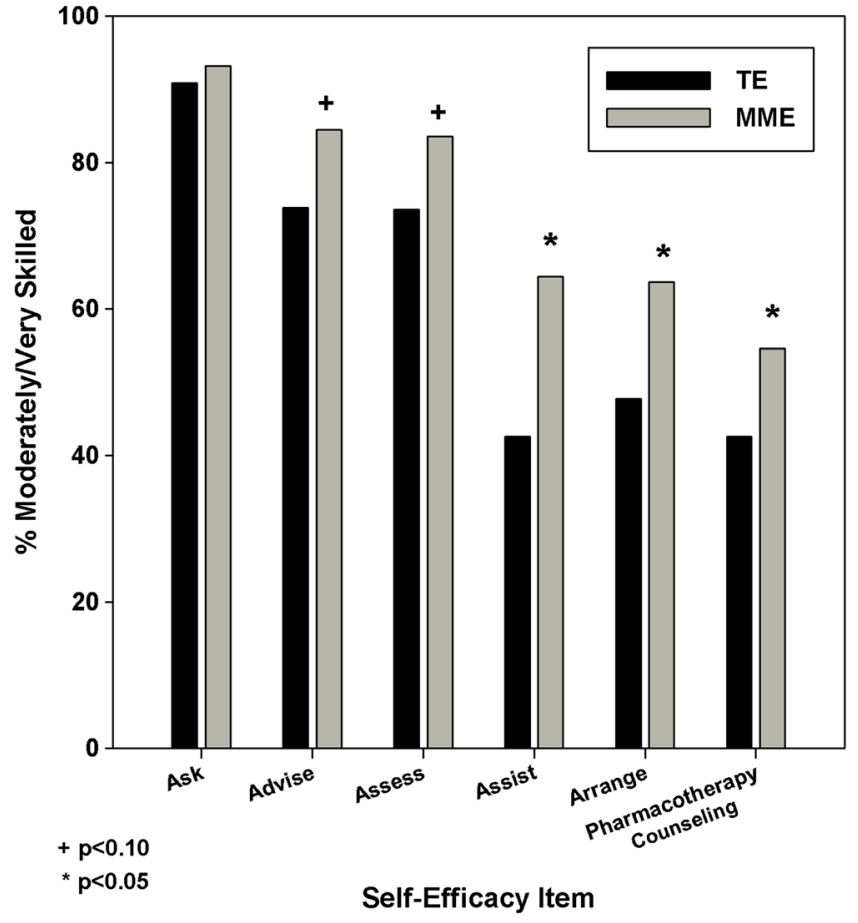

Fig. 2 Self-efficacy by randomization assignment

tobacco dependence treatment specialists. ${ }^{29}$ The four major components of the MSQuit intervention had high penetration (as measured by an objective tracking mechanism and via student self-report). The Academic Detailing ${ }^{18,19,30-35}$ component, albeit brief, resulted in MME MS3 students being more likely than TE students to report receipt on all measures of interest, including clear instruction, feedback, modeling, and clear objectives, for providing tobacco dependence treatment.

Despite more hours of tobacco dependence treatment training and strong indications of the receipt of tobacco dependence treatment education in years 1 and 3, total OSCE scores among MME students were low, and were not significantly higher than scores of TE students. There are several possible explanations. First, there was little room for improvement for the Ask and Assess measures, as both MME and TE students scored relatively high for these two behaviors at preintervention. This finding is consistent with the tobacco dependence treatment literature for practicing physicians, suggesting that this skill is already well-integrated into training programs. ${ }^{6}$ Second, achieving a higher total score on the OSCE may have been difficult, since third-year medical students rarely have in-depth or long-term contact with patients who smoke. Third, the time-limited nature of the OSCE may have precluded some students from asking additional questions or providing more counseling for components on which they had been well-trained. Notably, on the OSCE, only $61 \%$ of MME students were reported to advise patients to quit. However, more than $80 \%$ of students self-reported as moderately to very skilled in the Advise component of the 5As.
Fourth, there was no formal teaching for MME second-year students; thus there was a lapse of at least 18 months between the first-year pre-clinical component and the preceptor-led teaching and booster session for third-year students, which could have led to regression to original skills as first years. A more systems-oriented, longitudinal curriculum embracing the first three years of medical school might have been more beneficial. Fifth, a voluntary 30-60-min academic detailing program, while attended by more than $80 \%$ of MME preceptors, may have been insufficient to change preceptors' tobacco dependence treatment and precepting skills. In addition, the preceptor may have modeled a modified approach to the $5 \mathrm{As}$, such as Ask and Act, which has been promoted to practicing physicians in recent years. ${ }^{36}$

\section{STRENGTHS AND LIMITATIONS}

Major strengths evident in this study are the importance of assembling a team of physician and curriculum specialist innovators to develop and implement a medical education study, using a randomized design, with high fidelity across multiple and diverse medical schools, and rigorous evaluation via two time-tested methods for assessment and evaluation, notably an OSCE and student self-report.

The study may have limited generalizability, as only 10 of the 125 existing U.S. medical schools in 2009 were involved. Second, $\leq 4 \mathrm{~h}$ of tobacco treatment information in the curriculum was used as an inclusion criterion. This number indicates that the average number of hours for tobacco treatment training was based on current research at the time. Third, individual schools were not blinded to the type of educational intervention they were receiving. Fourth, while students were expected to complete a full $5 \mathrm{As}$ interaction with at least two patients who smoked, we cannot quantify the time students spent in tobacco counseling during the clerkship. While MME students reported greater preceptor-to-student tobacco dependence communication, there were no objective measures of the quantity or quality of the preceptors' training for individual students, nor was this standardized. Finally, the use of a single OSCE case may limit the generalizability of the results when considering variations in readiness to quit among patients.

\section{CONCLUSIONS}

Our findings highlight the continued need for additional tobacco dependence treatment training in U.S. medical schools, consistent with proposed reforms in undergraduate medical education by the Association of American Medical Colleges ${ }^{5}$ and he Institute of Medicine. ${ }^{37}$ Important lessons that emerged from the study were that educational models for such training should ideally include core knowledge building and role-play practice in medical school years 1 and 2, more intensive academic detailing and booster follow-up for medical school preceptors, and encounters with at least 2-3 smokers in clinical settings. 
The MSQuit study did not demonstrate a significant difference in the total OSCE score for MME students. However, the significant change in self-efficacy will likely result in eventual change in behavior or clinical performance. ${ }^{38}$ Heightened selfefficacy is an essential prerequisite for effecting a change in behavior. ${ }^{39}$ Likewise, learning occurs through a series of interactions that reinforce and layer on new, more complex skills over time. ${ }^{38}$ Building on what we have learned about tobacco treatment training for medical students will be an important next step.

Acknowledgments: The authors thank the participating medical schools, associate deans and medical education curriculum liaisons, our scientific advisory group, education and evaluation consultants, medical students, pre-clinical course directors, clerkship directors, preceptors, behaviorists, directors and trainers of standardized patients, and standardized patients for their participation in this study. We also thank the study coordinators, academic detailers, and research assistants at each medical school. We acknowledge our colleagues and study personnel at each medical school who were dedicated to the study and strongly contributed to its success. The National Cancer Institute had full administrative responsibility but had no role in the design or conduct of the study, or in the collection, management, analysis, or interpretation of the data.

Funding: The study was supported by an investigator-initiated grant from the National Cancer Institute (NCI) 5 R01 CA136888.

Prior Presentations: An earlier version of this work was presented orally at the 36th Annual Meeting of the Society of Behavioral Medicine, San Antonio, TX, on 24 April 2015.

Conflict of Interest: Sean P. David has stock partnership in Base Health. All other authors declare that they do not have a conflict of interest.

Disclaimer: The content is solely the responsibility of the authors and does not necessarily represent the official views of the National Cancer Institute, UMass Medical School, or participating medical schools.

Corresponding Author: Judith K. Ockene, PhD, MEd, MA; Division of Preventive and Behavioral Medicine, Department of MedicineUniversity of Massachusetts Medical School, 55 Lake Avenue North, Worcester, MA O 1655 , USA (e-mail: Judith.Ockene@umassmed.edu).

\section{REFERENCES}

1. Jamal A, Dube S, Malarcher A, Shaw L, Engstrom M, Office on Smoking and Health, et al. Tobacco use screening and counseling during physician office visits among adults - national ambulatory medical care survey and national health interview survey, United States, 2005-2009. MMWR Morb Mortal Wkly Rep. 2012;61:38-45.

2. U.S. Preventive Services Task Force. Counseling and interventions to prevent tobacco use and tobacco-caused disease in adults and pregnant women: U.S. Preventive services task force reaffirmation recommendation statement. Ann Intern Med. 2009;150(8):551-5.

3. Task Force on Community Preventive Services. Recommendations regarding interventions to reduce tobacco use and exposure to environmental tobacco smoke. Am J Prev Med. 2001;20(2):10-5.

4. Solberg LI, Asche SE, Boyle RG, Boucher JL, Pronk NP. Frequency of physician-directed assistance for smoking cessation in patients receiving cessation medications. Arch Intern Med. 2005;165(6):656-60.

5. Association of American Medical Colleges (AAMC). Physician behavior and practice patterns related to smoking cessation. Washington, DC: AAMC2007.

6. Guinn VP, Stevens VJ, Hollis JF, Rigotti NA, Solberg LI, Gordon NP, et al. Tobacco-cessation services and patient satisfaction in nine nonprofit HMOs. Am J Prev Med. 2005;29(2):77-84.

7. Griffith BN, Montalto NJ, Ridpath L, Sullivan K. Tobacco dependence curricula in US osteopathic medical schools: a follow-up study. J Am Osteopath Assoc. 2013;113(11):838-48. doi:10.7556/jaoa.2013.059.
8. Ferry LH, Grissino LM, Runfola PS. Tobacco dependence curricula in US undergraduate medical education. JAMA. 1999;282(9):825-9.

9. Richmond R, Zwar M, Taylor R, Hunnisett J, Hyslop F. Teaching about tobacco in medical schools; a worldwide study. Drug Alcohol Rev Sep. 2009;28(5):484-97.

10. Torabi MR, Tao R, Jay SJ, Olcott C. A cross-sectional survey on the inclusion of tobacco prevention/cessation, nutrition/ diet, and exercise physiology/fitness education in medical school curricula. J Natl Med Assoc. 2011;103(5):400-6.

11. Geller AC, Brooks DR, Powers CA, Brooks KR, Rigotti NA, Bognar B, et al. Tobacco cessation and prevention practices reported by second and fourth year students as US medical schools. J Gen Intern Med. 2008;23(7): 1071-6.

12. Institute of Medicine, National Academy of Sciences, editors. Reducing tobacco-related cancer incidence and mortality: workshop summary. National cancer policy summit; 2013; Washington, DC: National Academies Press.

13. National Research Council. Improving Medical Education: Enhancing the Behavioral and Social Science Content of Medical School Curricula. Council NR, editor. Washington DC: The National Academies Press. 2004.

14. Spangler JG, George G, Foley KL, Crandall SJ. Tobacco intervention training: current efforts and gaps in US medical schools. JAMA. 2002;288(9): 1102-9.

15. Geller AC, Lash TL, Siegel B, Annas GD, Prout MN. The primary care pediatrician's influence on medical student's performance of smoking assessments and counseling. Prev Med. 2005;41(1):47-52.

16. Fiore MC, Croyle RT, Curry SJ, Cutler CM, Davis RM, Gordon C, et al. Preventing 3 million premature deaths and helping 5 million smokers quit: a national action plan for tobacco cessation. Am J Public Health. 2004;94(2):205-10.

17. Stearns JA, Stearns MA, Davis AK, Chessman AW. The family medicine curriculum resource project structural framework. Fam Med. 2007;39(1):31-7.

18. Hayes RB, Geller A, Churchill L, Jolicoeur D, Murray DM, Shoben A, et al. Teaching tobacco dependence treatment and counseling skills during medical school: rationale and design of the Medical Students helping patients Quit tobacco (MSQuit) group randomized controlled trial. Contemp Clin Trials. 2014;37(2):284-93. doi:10.1016/j.cct.2014.01.008.

19. Soumerai SB, Avorn J. Principals of educational outreach ("academic detailing") to improve clinical decision making. JAMA. 1990;263(4):549-56.

20. Epstein RM. Assessment in medical education. N Engl J Med. 2007;356(4):387-96. doi:10.1056/NEJMra054784.

21. Barzansky B, Etzel SI. Medical schools in the United States, 2009-2010. JAMA. 2010;304(11):1247-54. doi:10.1001/jama.2010.1154.

22. Murray DM. Design and analysis of group-randomized trials. New York: Oxford University Press; 1998.

23. Mazor K, Clauser B, Cohen A, Alper E, Pugnaire M. The dependability of students' ratings of preceptors. Acad Med. 1999;74(10 Suppl):S19-21.

24. Fiore MC, Jaen CR, Baker TB, Bailey WC, Benowitz NL, Curry SJ, et al. Treating tobacco use and dependence: 2008 update. Clinical practice guideline. Rockville: USDHHS, Public Health Service; 2008.

25. Steinberg ML, Krejci JA, Collett K, Brandon TH, Ziedonis DM, Chen $\mathrm{K}$. Relationship between self-reported task persistence and history of quitting smoking, plans for quitting smoking, and current smoking status in adolescents. Addict Behav. 2007;32(7):1451-60.

26. Andridge RR. Quantifying the impact of fixed effects modeling of clusters in multiple imputation for cluster randomized trials. Biom J. 2011;53(1):57-74. doi: 10.1002/bimj.201000140.

27. SAS Institute I. SAS/AF ${ }^{\circledR} 9.3$ procedure guide. Cary: SAS Institute, Inc.; 2011.

28. R Development Core Team. R: a language and environment for statistical computing. Vienna, Austria: R Foundation for Statistical Computing. 4014.

29. Pbert L, Ockene JK, Ewy BM, Leicher ES, Warner D. Development of a state wide tobacco treatment specialist training and certification programme for Massachusetts. Tob Control. 2000;9:372-81.

30. Ockene JK, Guirk M, Goldberg RJ, Kristeller J, Donnelly G, Kalan KL, et al. A residents' training program for the development of smoking intervention skills. Arch Int Med. 1988;148:1039-45.

31. Goldstein MG. Pharmacotherapy for smoking cessation. The tobacco dependence treatment handbook. New York: The Guilford Press; 2003:230-48.

32. Gorin SS, Ashford AR, Lantigua R, Hossain A, Desai M, Troxel A, et al. Effectiveness of academic detailing on breast cancer screening among 
primary care physicians in an underserved community. J Am Board Fam Med. 2006;19(2):110-21.

33. Ockene JK, Lindsay EA, Hymowitz N, Giffen C, Purcell T, Pomrehn P, et al. Tobacco control activities of primary care physicians in the Community Intervention Trial for Smoking Cessation (COMMIT). Tob Control. 1997;6(suppl 2):S49-56.

34. Ockene JK, Ockene IS, Quirk ME, Hebert JR, Saperia GM, Luippold RS, et al. Physician training for patient-centered nutrition counseling in a lipid intervention trial. Prev Med. 1995;24:563-70.

35. Seager JM, Howell-Jones RS, Dunstan FD, Lewis MA, Richmond S, Thomas DW. A randomised controlled trial of clinical outreach education to rationalise antibiotic prescribing for acute dental pain in the primary care setting. Br Dent J. 2006;201(4):217-22. discussion 6.

36. American Academy of Family Physicians. Ask and Act. http://www.aafp. org/about/initiatives/ask-act.html. Accessed August 122015

37. Institute of Medicine, Committee on Quality of Health Care in America. Crossing the quality chasm: a new health system for the 21 st century. Washington, DC: National Academy Press; 2001.

38. Bandura A. Social learning theory. Englewood Cliffs: Prentice-Hall; 1977.

39. Bandura A. Self-efficacy: toward a unifying theory of behavioral change. Psychol Rev. 1977;84:191-215. 